\section{Day vs. night in spinal cord injury}

\section{By Kai-Jye Lou, Staff Writer}

Patients with chronic spinal cord injuries often develop spasticity, but the underlying mechanisms remain unclear. Now, a group from the University of Alberta has uncovered a receptor involved in the process: a constitutively active isoform of the serotonin $\left(5-\mathrm{HT}_{2 \mathrm{C}}\right)$ receptor. ${ }^{1}$ Targeting the receptor could be tricky, though, because in addition to fostering spasticity, the receptor also promotes motor recovery from the actual injury.

One option could be to agonize the receptor during the day to help motor recovery and antagonize it at night so the spasticity doesn't interfere with a patient's ability to sleep.

In spinal cord injury (SCI), neurons below the injury site lose their supply of serotonin (5-HT) from the brain stem, which leaves these cells in an unexcitable state. This loss of motor neuron excitability is one factor that contributes to muscle paralysis in SCI.

Despite the lack of serotonin, some motor neurons spontaneously regain their excitability in the weeks or months following injury via unknown mechanisms. Although this helps the recovery of motor function, it also leads to spasticity because some inputs from the brain that normally would prevent excessive excitability are absent.

"Despite many years of research, there are still no definite theories on why spasticity develops in chronically injured patients," said Serge Rossignol, the Canada Research Chair on the Spinal Cord and a professor in the Department of Physiology and Neurological Sciences at the University of Montreal. "The exciting aspect of the current work is that the researchers focused on one neurotransmitter and one receptor and went through the basic pharmacological studies to link aspects of locomotor recovery and muscle spasticity to a change that happens in a specific serotonin receptor."

The Alberta group showed that expression of a highly constitutively active isoform of the serotonin $\left(5-\mathrm{HT}_{2 \mathrm{C}}\right)$ receptor $\left(\mathrm{HTR}_{2 \mathrm{C}}\right)$ in motor neurons is upregulated in chronic SCI. Unlike other isoforms, this isoform is highly active even in the absence of serotonin (see Figure 1, "A molecular mechanism involved in recovery and spasticity"). ${ }^{2}$

The group showed that upregulated expression of the isoform corresponded to increased cell excitability, which in turn contributed to both motor recovery and the emergence of muscle spasticity.

The researchers showed that post-transcriptional editing at a particular site on $5-\mathrm{HT}_{2 \mathrm{C}}$ receptor mRNA was significantly lower in the motor neurons of rats with chronic SCI than in those of uninjured controls $(p<0.05)$. This difference in editing efficiency corresponded to a fourfold increase in the expression of the unedited $5-\mathrm{HT}_{2 \mathrm{C}}$ receptor isoform, which increased motor neuron excitability compared with that in uninjured controls ( $p<0.01$ for both).

In a rat model of chronic SCI, intrathecal delivery of a selective $5-\mathrm{HT}_{2 \mathrm{C}}$ receptor inverse agonist reduced tail spasms compared with delivery of saline control. In an investigator-led trial in chronic SCI patients, treatment with cyproheptadine, a marketed, nonselective $5-\mathrm{HT}_{2}$ receptor inhibitor, significantly decreased leg muscle spasms compared with vehicle $(p<0.01)$.

Cyproheptadine is a generic drug approved to treat allergies and hay fever. About 30 years ago, cyproheptadine was also shown to reduce spasticity and improve locomotion in SCI. It is still being used off-label to treat muscle spasticity in SCI patients but has multiple side effects like increased food intake and weight gain. Merck \& Co. Inc. markets a branded version of the drug under the name Periactin.

Although cyproheptadine is known to inhibit serotonin signaling through the 5- $\mathrm{HT}_{2}$ receptors, including $5-\mathrm{HT}_{2 \mathrm{C}}$, it was unclear how such receptors contribute to the emergence of spasticity in chronic SCI.

The results were published in Nature Medicine.

"We show that this increased excitability in the spinal cord is caused by serotonin receptors spontaneously turning on in the absence of serotonin," said David Bennett, co-senior author of the paper and a professor of rehabilitation medicine at the University of Alberta. "The challenge now is to design therapies to, on one hand, harness this spontaneous recovery of spinal cord function to help recover useful function and, on the other hand, turn off excessive spinal cord activity when it is not needed."

"Our work identifies one mechanism that seems to contribute to both recovery of locomotor activity and the development of spasticity," added Karim Fouad, co-senior author and professor of rehabilitation medicine at the university. "This suggests that we will have to be very careful when targeting the serotonin pathway to treat chronically injured patients for spasticity. We will need to make sure the drugs we give don't also block the recovery of locomotor function."

"I thought this study was compelling in that it gives a rather convincing argument for receptors becoming constitutively active after spinal cord injury," said Vivian Mushahwar, an associate professor of cell biology at the university who was not involved with the current study. "This work implicates not only the receptor but also a particular change in the receptor that contributes to spasticity."

\section{Molecular insights for new treatments}

By shedding some light on the molecular pathways involved in the emergence of muscle spasticity following chronic SCI, the findings could provide a road map for developing therapies that enhance recovery but prevent spasticity.

"In chronically injured patients that want to walk during the day, you might be able to treat them with citalopram, which is an SSRI, to increase $5-\mathrm{HT}_{2 \mathrm{C}}$ signaling, and then when the patients want to sleep, you could give them a drug that blocks $5-\mathrm{HT}_{2 \mathrm{C}}$, like cyproheptadine," said Fouad. 
Figure 1. A molecular mechanism involved in recovery and spasticity. In Nature Medicine, researchers show that increased expression of a serotonin $\left(5-\mathrm{HT}_{2 \mathrm{C}}\right)$ receptor $\left(\mathrm{HTR}_{2 \mathrm{C}}\right)$ isoform with high constitutive activity mediates both the recovery of motor function and the emergence of muscle spasticity in chronic spinal cord injury (SCI).

Post-transcriptional editing is known to occur at five sites (arrows) on 5- $\mathrm{HT}_{2 \mathrm{C}}$ receptor mRNA. Edited mRNAs code for $5-\mathrm{HT}_{2 \mathrm{C}}$ receptor isoforms that have less constitutive activity than receptors generated from unedited mRNAs.

Editing results in the substitution of different amino acids (red circles) at positions 156, 158 and 160 on the protein transcript. Receptor isoforms are named based on the amino acid present at these three positions.

The researchers showed that in chronic $\mathrm{SCl}$, mRNA editing efficiency is decreased at one of the known edit sites on 5- $\mathrm{HT}{ }_{2 \mathrm{C}}$ receptor mRNA (red arrow). This change in mRNA editing corresponds to decreased expression of the VNI isoform and increased expression of the INI isoform.

The researchers propose that this change in mRNA editing efficiency could be responsible for increased expression of the highly active INI receptor isoform, which in turn contributes to the increase in motor neuron excitability seen in chronic SCl.
Citalopram is a generic selective serotonin reuptake inhibitor (SSRI). H. Lundbeck A/S and Forest Laboratories Inc. market the drug as Celexa to treat depression.

By blocking serotonin reuptake, more serotonin becomes available to activate its receptors-like the $5-\mathrm{HT}_{2 \mathrm{C}}$ receptor.

The most widely used drug for spasticity is baclofen, a generic $\mathrm{GABA}_{\mathrm{B}}$ receptor agonist. "While the drug has a strong inhibitory effect, it also works nonspecifically, and patients can overdose and experience other negative side effects like hallucinations," Mushahwar told SciBX. "Maybe the doses of baclofen can be reduced considerably if it is combined with a drug that specifically targets the $5-\mathrm{HT}_{2 \mathrm{C}}$ receptor. Targeted drugs may be able to control spasticity with a better side-effect profile."

Rossignol thinks the contribution of other pathways to the recovery of motor function and spasticity needs to be elucidated.

"After spinal cord injury, multiple pathways that provide the spinal cord with signaling molecules produced in other parts of the nervous system are lost," he told SciBX. "They have looked at serotonin receptors, but there are other receptors that might be changed as well when the spinal cord is injured, like GABA and noradrenergic receptors. Quite clearly, much more research is needed to understand what these and other receptors are doing after spinal cord injury."

Rossignol also wanted to know whether reducing spasticity impairs motor function recovery and how one would balance the use of serotonin receptor agonists and antagonists.

Fouad said the Alberta group is further dissecting the identified pathway to find ways to prevent excessive activity in motor neurons while also increasing recovery of motor function. He said it will be important to explore whether these receptors are involved in the functional recovery of the sensory system and whether other receptors can become constitutively active in chronic SCI.

Bennett added that the group also has an ongoing investigator-run trial evaluating the use of citalopram in chronic SCI patients.

The work is not patented.

Lou, K.J. SciBX 3(25); doi:10.1038/scibx.2010.751

Published online June 24, 2010

REFERENCES

1. Murray, K.C. et al. Nat. Med.; published online May 27, 2010; doi:10.1038/nm.2160

Contact: David Bennett, University of Alberta, Edmonton, Alberta, Canada e-mail: bennettd@ualberta.ca

2. Berg, K.A. et al. J. Pharmacol. Exp. Ther. 324, 1084-1092 (2008)

COMPANIES AND INSTITUTIONS MENTIONED

Forest Laboratories Inc. (NYSE:FRX), New York, N.Y. H. Lundbeck A/S (CSE:LUN), Copenhagen, Denmark Merck \& Co. Inc. (NYSE:MRK), Whitehouse Station, N.J. University of Alberta, Edmonton, Alberta, Canada University of Montreal, Montreal, Quebec, Canada 